\title{
CLIMATE CHANGE IN NORTHERN AFRICA: THE PAST IS NOT THE FUTURE
}

\author{
MARTIN CLAUSSEN ${ }^{1,2}{ }^{2}$, VICTOR BROVKIN ${ }^{1}$, ANDREY GANOPOLSKI ${ }^{1}$, \\ CLAUDIA KUBATZKI ${ }^{1}$ and VLADIMIR PETOUKHOV ${ }^{1}$ \\ ${ }^{1}$ Potsdam-Institut für Klimafolgenforschung, Postfach 601203, D-14412 Potsdam, Germany \\ E-mail: claussen@pik-potsdam.de \\ ${ }^{2}$ Institut für Meteorologie, FU Berlin, C.-H. Becker Weg 6-10, D-12165 Berlin, Germany
}

\begin{abstract}
By using a climate system model of intermediate complexity, we have simulated longterm natural climate changes occurring over the last 9000 years. The paleo-simulations in which the model is driven by orbital forcing only, i.e., by changes in insolation caused by changes in the Earth's orbit, are compared with sensitivity simulations in which various scenarios of increasing atmospheric $\mathrm{CO}_{2}$ concentration are prescribed. Focussing on climate and vegetation change in northern Africa, we recapture the strong greening of the Sahara in the early and mid-Holocene (some 9000-6000 years ago), and we show that some expansion of grassland into the Sahara is theoretically possible, if the atmospheric $\mathrm{CO}_{2}$ concentration increases well above pre-industrial values and if vegetation growth is not disturbed. Depending on the rate of $\mathrm{CO}_{2}$ increase, vegetation migration into the Sahara can be rapid, up to 1/10th of the Saharan area per decade, but could not exceed a coverage of $45 \%$. In our model, vegetation expansion into today's Sahara is triggered by an increase in summer precipitation which is amplified by a positive feedback between vegetation and precipitation. This is valid for simulations with orbital forcing and greenhouse-gas forcing. However, we argue that the mid-Holocene climate optimum some 9000 to 6000 years ago with its marked reduction of deserts in northern Africa is not a direct analogue for future greenhouse-gas induced climate change, as previously hypothesized. Not only does the global pattern of climate change differ between the midHolocene model experiments and the greenhouse-gas sensitivity experiments, but the relative role of mechanisms which lead to a reduction of the Sahara also changes. Moreover, the amplitude of simulated vegetation cover changes in northern Africa is less than is estimated for mid-Holocene climate.
\end{abstract}

\section{Introduction}

Paleoclimatic reconstructions indicate that during the so-called Holocene climatic optimum some 9000-6000 years ago, the summer in the northern hemisphere was warmer than today. The summer monsoon in northern Africa was stronger than today according to lake level reconstructions (Yu and Harrison, 1996), estimates of aeolian dust fluxes (deMenocal et al., 2000), and distribution sand dunes (Sarnthein, 1978). Moreover, paleobotanic data (Jolly et al., 1998) reveal that the Sahel reached at least as far north as $23^{\circ} \mathrm{N}$. (The present boundary extends up to $18^{\circ} \mathrm{N}$.) Hence, there is an overall consensus that during the Holocene optimum, the Sahara was greener than today - albeit reconstruction of mid-Holocene vegetation distribution in northern Africa vary (Frenzel et al., 1992; Hoelzmann et al., 1998; 
Anhuf et al., 1999, Prentice et al., 2000) with respect to vegetation coverage and geographical detail. Further paleoclimatic evidence (Sarnthein, 1978; Sarnthein et al., 1981; Maslin et al., 1996) suggests that the expansion and retreat of Sahara parallels climate changes in the northern hemisphere. During the peak phase of an interglacial, such as the Eemian and the Holocene optimum, the desert shrank, i.e., the Sahara became greener, and during colder climate, in particular during a glacial, the desert expanded.

The parallel course of vegetation expansion and increase in northern hemisphere mean temperatures has provoked the hypothesis that the Sahara would become greener again if anthropogenic greenhouse-gas emissions continue to increase and if, therefore, the global climate again becomes warmer and moister (Petit-Maire, 1990). Such paleo-analogues are mainly based on statistical correlation, rather than physical reasoning. From the physical point of view, there are obvious differences between the forcings which drive climate change. Variations between glacials and interglacials are presumably driven by, or at least triggered by, changes in the Earth's orbit around the sun (e.g., Spitaler, 1921; Kutzbach and Guetter, 1986; Berger and Loutre, 1997) which induce regional and seasonal variations in insolation. An increase in greenhouse gases, on the other hand, affects climate on the global scale, because global dispersion of these gases is much faster than their lifetime in the atmosphere. Hence it has to be questioned whether the midHolocene optimum is a direct paleo-analogue of a greenhouse-gas induced climate change. In particular, it is not at all obvious whether an increase in atmospheric $\mathrm{CO}_{2}$ concentration could lead to a greening of the Sahara.

It is known that climate models yield equivocal results with respect to changes in northern African precipitation in a greenhouse-gas induced climate change. Model sensitivity experiments (Cubasch et al., 2001) show that an increase in greenhouse gas concentration leads to a warmer near-surface atmosphere, with the land surface warming faster than the ocean surfaces. Concerning precipitation, the model survey suggests an increase in most tropical areas and a decrease in most subtropical areas. However, there appears to be a high intermodel variability concerning the exact location of the transition zone and therefore little consistency among models with respect to simulated changes of precipitation in northern African.

Moreover, most climate models do not take into account vegetation dynamics. This could be a serious drawback when tackling the question of climate change in northern Africa as seen in paleoclimatic simulations. Results from the Paleoclimatic Modeling Intercomparison Project (PMIP) reveal that no model yields an increase in precipitation large enough to lead to a substantial reduction of the Sahara in the mid-Holocene climate, when the land cover was prescribed according to present-day conditions (Joussaume et al., 1999; Harrison et al., 1998). When, however, more realistic land-cover conditions were prescribed (Kutzbach et al., 1996; Broström et al., 1998), or when feedbacks between changing atmosphere and changing vegetation were taken into account (Claussen and Gayler, 1997; 
Texier et al., 1997; Ganopolski et al., 1998a, Braconnot et al., 1999), then a more realistic climate change including a reduction in the Saharan and Arabian deserts was found. Presumably, orbital forcing just triggers climate changes in northern Africa, and these are then amplified by feedbacks within the climate system (e.g., Claussen et al., 1998). Therefore, we use CLIMBER-2, a coupled atmosphereocean-vegetation model of intermediate complexity, to explore the possibility of vegetation expansion in arid northern Africa if atmospheric $\mathrm{CO}_{2}$ concentrations increase, and we compare the results of this sensitivity study with paleoclimatic simulations of the last 9000 years.

\section{Model Description and Experiment Set Up}

The CLIMBER-2 model (for Climate-Biosphere model, version 2) is described in detail in Petoukhov et al. (2000) and Ganopolski et al. (2001). CLIMBER-2 has a coarse resolution of 10 degrees in latitude and approximately 51 degrees in longitude in the atmosphere. The model of the atmosphere is based on the statistical-dynamical approach and describes synoptic variability in terms of second moments (auto- and cross-correlation functions of deviations from the long-term values of the atmospheric variables). It resolves the slow tropical dynamics; the extratropical synoptic fluxes of heat and moisture are parameterized as diffusion terms. The vertical structures of temperature and specific humidity and the atmospheric mean meridional circulation are parameterized and then used for calculating the three-dimensional advective, diffusive and radiative fluxes. The latter are evaluated using a multilevel (16 levels) radiation scheme that accounts for water vapor, $\mathrm{CO}_{2}$, aerosols and cloudiness. The ocean model is a multi-basin, zonally averaged model similar to that of Stocker et al. (1992), including a model of sea-ice thickness, concentration and advection. The model of terrestrial vegetation (Brovkin et al., 2002) describes vegetation structure, i.e., fractional coverage of a grid cell by trees, grass, and desert, as well as net primary productivity (NPP), leaf area index (LAI), biomass and soil carbon pools. The vegetation structure depends on the temperature and precipitation fields, while NPP, LAI and carbon pools depend also on atmospheric $\mathrm{CO}_{2}$ concentration. The time scale of vegetation dynamics are of the order of decades to centuries for trees and of the order of years for grass. To account for the absence of soil and nutrients in desert regions, the time scale of vegetation growth in former deserts or semi deserts is set to that of trees whenever the vegetation fraction is below a critical value of 0.1 . With respect to the vegetation dynamics and changes in the carbon budget in simulations with prescribed changes in atmospheric $\mathrm{CO}_{2}$ concentration, the vegetation model agrees well with other dynamic global vegetation models (Cramer et al., 2001).

The CLIMBER-2 model not only realistically reproduces the large-scale pattern of present-day climate (Petoukhov et al., 2000). Also, which is important for this study, the sensitivity of CLIMBER-2 to changes in external forcing, such 


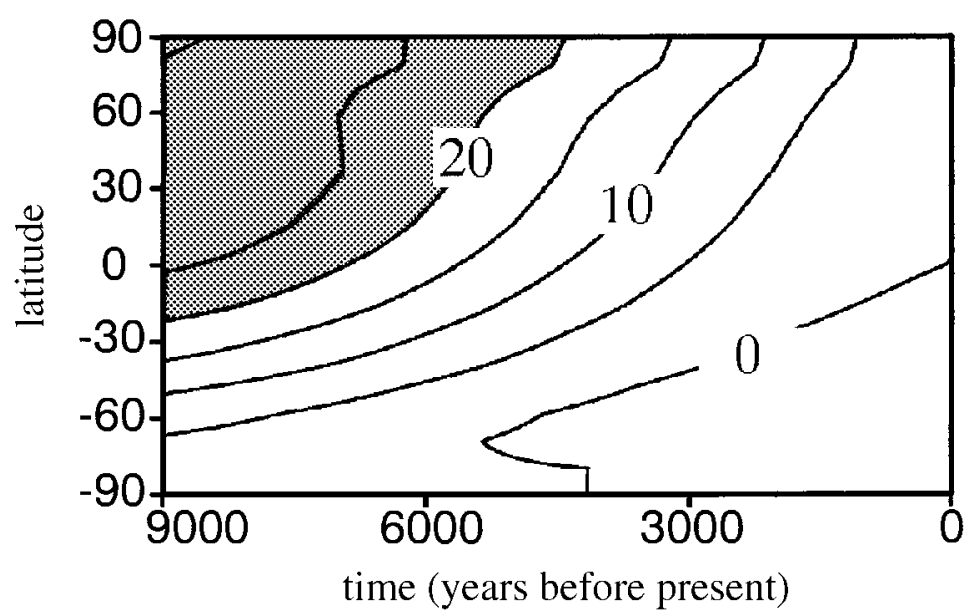

Figure 1. Changes in boreal summer (June, July, August) insolation (in $\mathrm{W} \mathrm{m}^{-2}$ ) caused by changes in Earth's orbital parameters depicted as function of latitude and time during the last 9000 years.

as changes in atmospheric $\mathrm{CO}_{2}$ concentration, solar irradiation, freshwater input to the North Atlantic, and boreal and tropical deforestation, is similar to that of comprehensive models of atmospheric and oceanic circulation (Ganopolski et al., 2001). Moreover, CLIMBER-2 has successfully been applied to paleoclimatic simulations of the last glacial maximum (Ganopolski et al., 1998b) and the Eemian (Kubatzki et al., 2000), for example.

CLIMBER-2 has also been used to reproduce the reduction of Saharo-Arabian deserts during the Holocene optimum (Ganopolski et al., 1998a) and the transition from the Holocene optimum to present-day climate (Claussen et al., 1999; deMenocal et al., 2000). These studies were undertaken by using CLIMBER-2.1. Therefore, we have repeated the experiments using the updated version CLIMBER2.3. Versions 2.1 and 2.3 differ mainly in an increased spatial resolution in the ocean model and some changes in the numerical scheme to assure better numerical stability. Thus, results obtained with CLIMBER-2.3 and with CLIMBER-2.1 remain the same qualitatively, though there are some minor quantitative differences (see below).

In the paleoclimatic simulations - referred to as the Holocene experiments in the following - seasonal and regional insolation pattern were computed from changes in orbital forcing for the last 9000 years (Berger, 1978). Differences in boreal summer insolation over the past 9 ky BP (9000 years before present) and today are shown in Figure 1. In the Holocene experiments, pre-industrial ice cover and atmospheric $\mathrm{CO}_{2}$ concentration were chosen to better compare effects of orbital forcing and radiative forcing. Changes in orbital forcing over the last few centuries and for the few centuries to come are negligibly small.

The $\mathrm{CO}_{2}$ sensitivity experiments were set up in the following way. The coupled atmosphere-ocean-vegetation model was run for 10,000 years to an equilibrium 


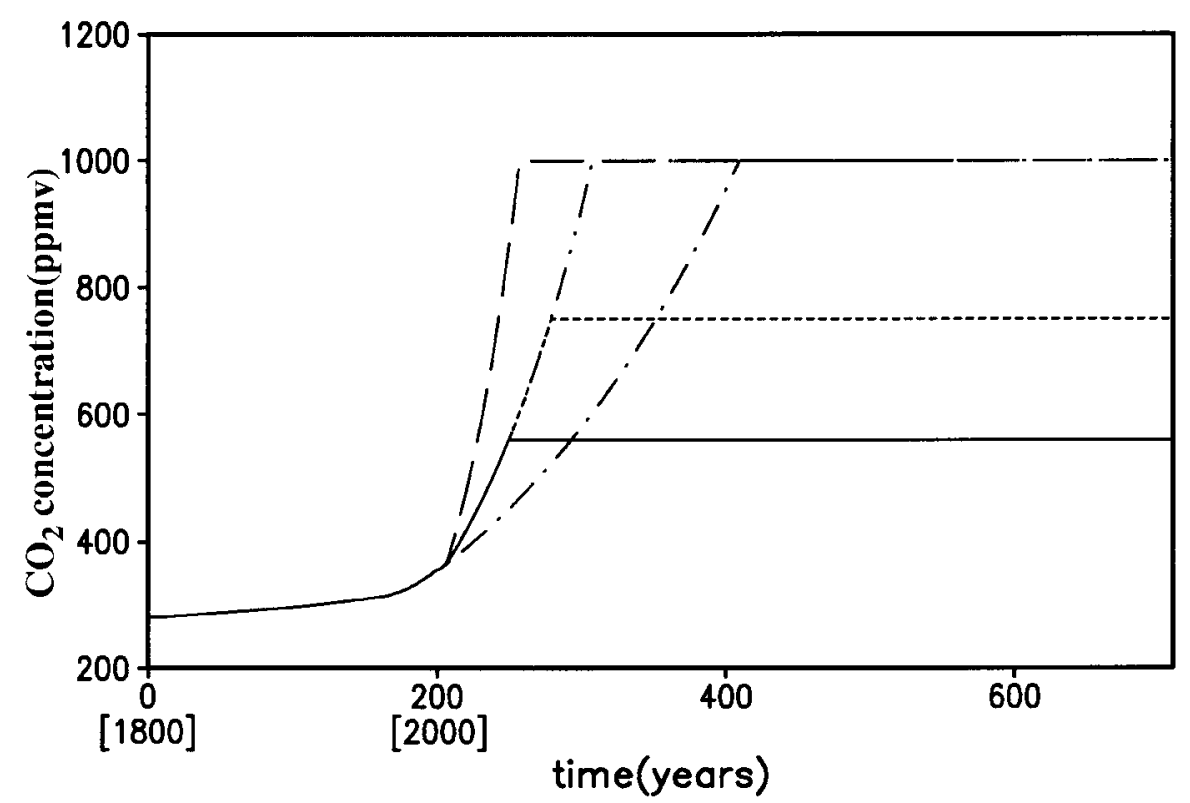

Figure 2. Scenarios of increase in atmospheric $\mathrm{CO}_{2}$ concentrations. For the first 200 years of simulation, the atmospheric $\mathrm{CO}_{2}$ concentration reconstructed and observed for the years $1800 \mathrm{AD}$ to $1999 \mathrm{AD}$ are prescribed. Thereafter various scenarios of $\mathrm{CO}_{2}$ increase are chosen: An increase of $1 \%$ per year up to a concentration of $560 \mathrm{ppmv}$ (full line), $750 \mathrm{ppmv}$ (short-dashed line), $1000 \mathrm{ppmv}$ (dot-dot-dashed line), an increase of $0.5 \%$ per year (dot-dashed line) and of $2 \%$ per year (dashed line), respectively up to $1000 \mathrm{ppmv}$.

with pre-industrial insolation, distribution of inland ice, and atmospheric $\mathrm{CO}_{2}$ concentration. This simulation is referred to as the control simulation. Then, atmospheric $\mathrm{CO}_{2}$ concentration was changed from its preindustrial value of 280 ppmv as derived from reconstructions (Neftel et al., 1990) and observations (Keeling, 2000) from 1800 to 1999. After 1999, atmospheric $\mathrm{CO}_{2}$ concentrations were increased by $1 \%$ per year to a value of $560 \mathrm{ppmv}, 750 \mathrm{ppmv}$, and $1000 \mathrm{ppmv}$, respectively. After the maximum $\mathrm{CO}_{2}$ concentration is reached, it is kept constant. To explore the sensitivity of the model climate to variations in the rate of forcing we also chose a $0.5 \%$ per year and a $2 \%$ per year increase for the case of the 1000 ppmv maximum $\mathrm{CO}_{2}$ concentration (see Figure 2). In the following, these experiments are referred to as the 560-1, 750-1, 1000-1, 1000-0.5 and 1000-2 simulations, respectively.

Most experiments were undertaken using the fully coupled model. However, to explore the impact of atmosphere-vegetation feedbacks, including their synergisms with atmosphere-ocean feedbacks, we compare results of the fully coupled model with the respective results of the atmosphere-ocean model in which the land cover was kept constant at conditions computed for pre-industrial climate. 


\section{Sensitivity of Global Climate to Holocene Orbital Forcing and Increased Atmospheric $\mathrm{CO}_{2}$ Concentrations}

The global pattern of differences in near-surface temperatures during the boreal summer (June, July, August) between the Holocene simulation at 6 ky BP and the control simulation (Figure 3a) reveal a warming over Central Eurasia and North America. (We analyse model results at $6 \mathrm{ky} \mathrm{BP}$, because most model studies on mid-Holocene climate focus on this time period, see Joussaume et al., 1999.) These changes can partly be interpreted as a direct response of the climate system to orbital forcing (see Figure 1) which led to a strong warming of high northern continents and little change in the southern hemisphere during the boreal summer. At high northern latitudes the temperature change triggered by orbital forcing was presumably amplified by internal feedbacks, in particular by a synergism between temperature changes owing to a reduction in Arctic sea-ice and an expansion in boreal vegetation (Claussen, 2001). Summer precipitation increases in comparison with pre-industrial climate mainly in the monsoon areas of Africa, Asia and, to a lesser extent, of North and South America (Figure 3c). Reduced precipitation is found mainly in the southern subtropics and in Europe. Changes in African summer precipitation are much weaker in simulations in which vegetation dynamics are ignored (Ganopolski et al., 1998a). This result is in qualitative agreement with most model experiments on paleo-monsoon (Kutzbach et al., 2001). This leads to the conclusion that the African summer monsoon, and thus Saharan greening, was strongly amplified by vegetation-atmosphere interaction in northern Africa.

In the $\mathrm{CO}_{2}$ sensitivity experiments global mean temperature and precipitation increase until the maximum values of $\mathrm{CO}_{2}$ concentration are reached. Thereafter, the system - owing to the thermal inertia of the deep ocean - slowly approaches a new equilibrium. In the case of a doubling of $\mathrm{CO}_{2}$ concentration, the global mean temperature has increased by $2.7 \mathrm{~K}$ and global mean precipitation by $10 \%$ in the equilibrium state. These values are within the range of results from comprehensive models (e.g., Cubasch et al., 2001).

The warming caused by an increase in atmospheric $\mathrm{CO}_{2}$ concentrations is strongest at the respective winter polar region (Figure 3b). Temperature increase is stronger over the continents than over the oceans (see Ganopolski et al., 2001 for a more detailed discussion). However, the zonal temperature differences over the northern hemisphere are weaker than in the mid-Holocene simulation (Figure 3a). Boreal summer precipitation increases in the tropics, particularly over SouthEast Asia. It decreases over the southern subtropics and over southern Europe (Figure 3d).

Regarding changes in precipitation, many climate models (see Cubasch et al., 2001) reveal an increase in precipitation in tropical Africa and the Sudan and a decrease in summer precipitation in southern Europe and the Mediterranean region in the case of an increase of atmospheric $\mathrm{CO}_{2}$ concentrations. Given the variability among model results, the sign of change in Saharan precipitation seems to be equiv- 

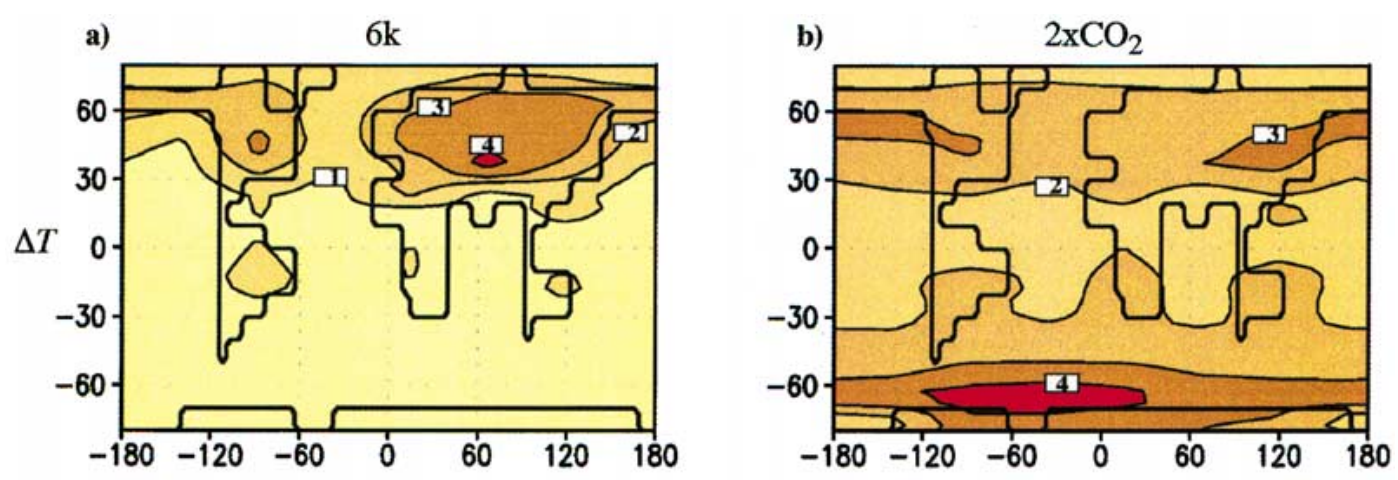

c)

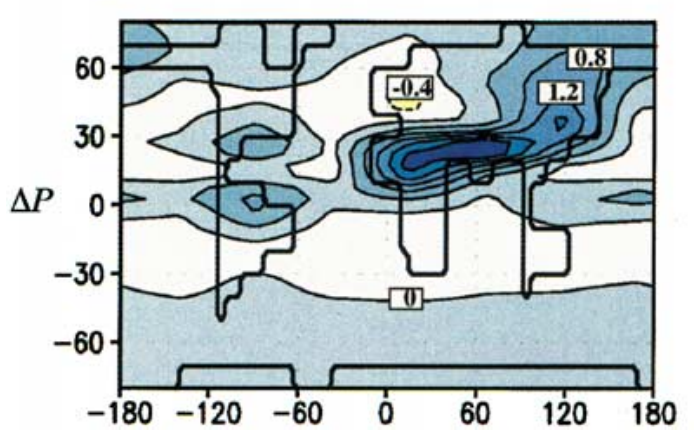

d)

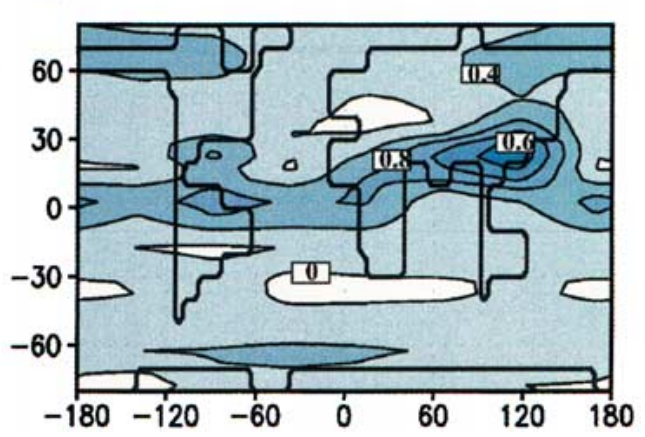

Figure 3. Global patterns of differences in boreal summer (June, July, August) temperature T (in ${ }^{\circ} \mathrm{C}$ ) $(\mathrm{a}, \mathrm{b})$ and boreal summer precipitation $\mathrm{P}$ (in $\mathrm{mm} / \mathrm{day}$ ) (c, d) between mid-Holocene climate some 6000 years ago and pre-industrial climate $(\mathrm{a}, \mathrm{c})$ and between a climate adjusted to atmospheric $\mathrm{CO}_{2}$ concentrations of 560 ppmv and pre-industrial climate (b, d).

ocal. Some models predict a more arid climate, others a more humid climate. For example, Colman et al. (1995) reported a rather strong increase of 1-2 mm/day in the Sahel region and in North-West Africa during the boreal summer as a response to a doubling of atmospheric $\mathrm{CO}_{2}$ concentrations.

\section{Changes in Northern Africa}

Figure 4 shows transient changes in the Saharan vegetation fraction and precipitation resulting from the Holocene experiment. The vegetation in the Sahara consists mainly of grassland. Saharan vegetation coverage follows the steady change in northern hemisphere insolation in a disproportional way. During the early and late Holocene, Saharan vegetation coverage changes more slowly than insolation, in the mid-Holocene, around $6 \mathrm{ky} \mathrm{BP,} \mathrm{much} \mathrm{faster.} \mathrm{This} \mathrm{non-linear} \mathrm{behavior} \mathrm{has} \mathrm{been}$ attributed to the non-linear vegetation-atmosphere feedback (Claussen et al., 1999). As mentioned above, the results presented here slightly differ from those discussed 


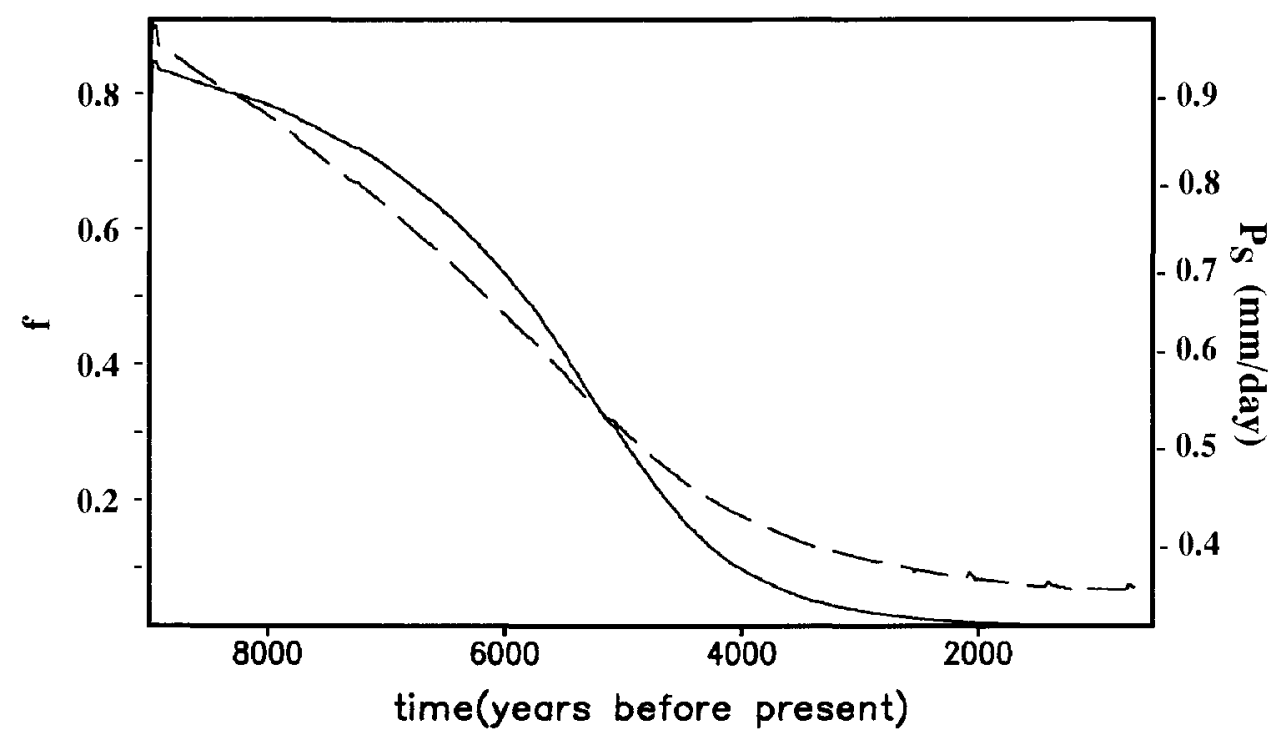

Figure 4. Simulated Saharan vegetation fraction (full line) and annual mean precipitation $P_{S}$ (in $\mathrm{mm} /$ day; dashed line) during the last 9000 years.

earlier (Claussen et al., 1999). The vegetation fraction in the Sahara at 6 ky BP reaches 0.71 in CLIMBER-2.1 and 0.52 in CLIMBER-2.3.

In the $\mathrm{CO}_{2}$ sensitivity experiments, the model reveals only marginal changes in Saharan vegetation cover (see Figure 5a) during the first 220 to 250 years of simulation. Thereafter, a rather strong increase in vegetation cover (consisting of grassland) is seen. The amplitude as well as the rate of vegetation change depend on the amplitude and rate of $\mathrm{CO}_{2}$ changes. The higher the value at which $\mathrm{CO}_{2}$ concentrations stabilize, the more significant are the vegetation changes. In the 560-1 simulation, the maximum vegetation cover stays well below 0.1 (i.e., less than $10 \%$ of the Saharan area is covered by vegetation), while in the $1000-2$ simulation it reaches values of approximately 0.45 . Similarly, a stronger $\mathrm{CO}_{2}$ growth rate results in a more abrupt vegetation change. In the 1000-0.5 and the 10002 simulation, vegetation increases to maximum values within approximately 20 decades and 5 decades, respectively. The vegetation cover in the Sahara reaches its maximum a few decades after the atmospheric $\mathrm{CO}_{2}$ concentration has gained its maximum value. Thereafter, Saharan vegetation declines. The amplitude of decline can be quite strong: for example, in the case of the 1000-1 simulation vegetation shrinks from approximately 0.43 to 0.30 .

The non-linear response of Saharan vegetation to monotonous $\mathrm{CO}_{2}$ forcing is also seen in the changes of precipitation (Figure 5b). Both vegetation and precipitation changes closely follow the transient changes in temperature gradients between land surface in northern Africa and the ocean surface of the tropical North Atlantic (Figure 6a). Owing to its larger heat capacity, the ocean warms more 

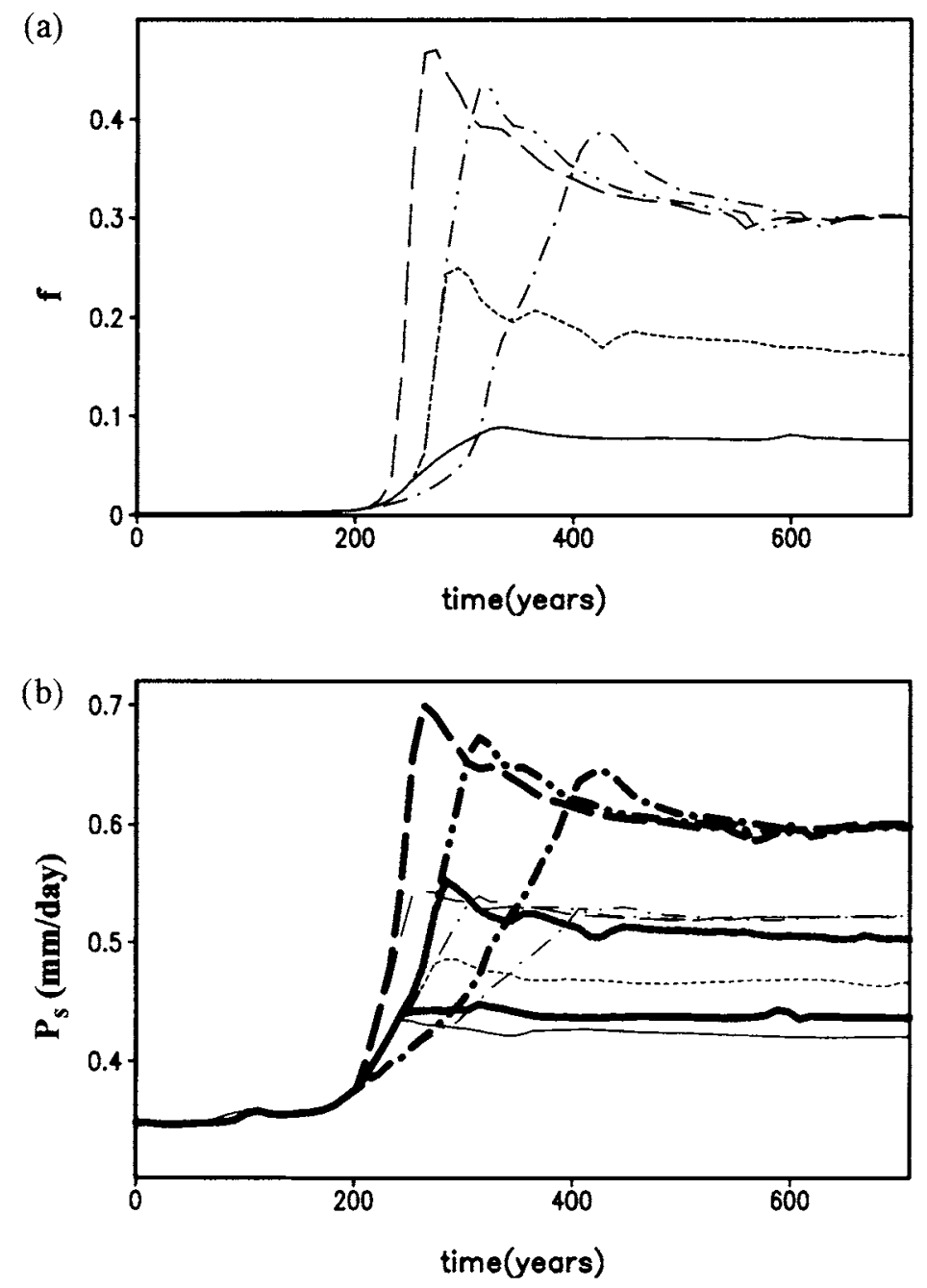

Figure 5. Saharan vegetation fraction (a) and annual mean precipitation $P_{S}$ (in $\mathrm{mm} /$ day) (b) as function of model years for different scenarios of changes in atmospheric $\mathrm{CO}_{2}$ concentrations. The signature of curves refers to the $\mathrm{CO}_{2}$ scenarios depicted in Figure 2. The thin curves in (b) refer to results of the atmosphere-ocean-only model, the thick curves to results of the fully coupled model.

slowly than the continent. However, when the forcing is kept constant, i.e., when the atmospheric $\mathrm{CO}_{2}$ concentration has reached its maximum value and is kept constant, then the ocean 'catches up'.

While the transient changes in regional land-ocean contrast seem to dominate the monsoon changes in northern Africa, the situation is more complex in the Holocene experiment. It appears (Figure 6b) that the changes in African precipitation, which were triggered by orbital forcing during the last 9000 years, parallel the transient changes in the large-scale surface temperature gradient between the 

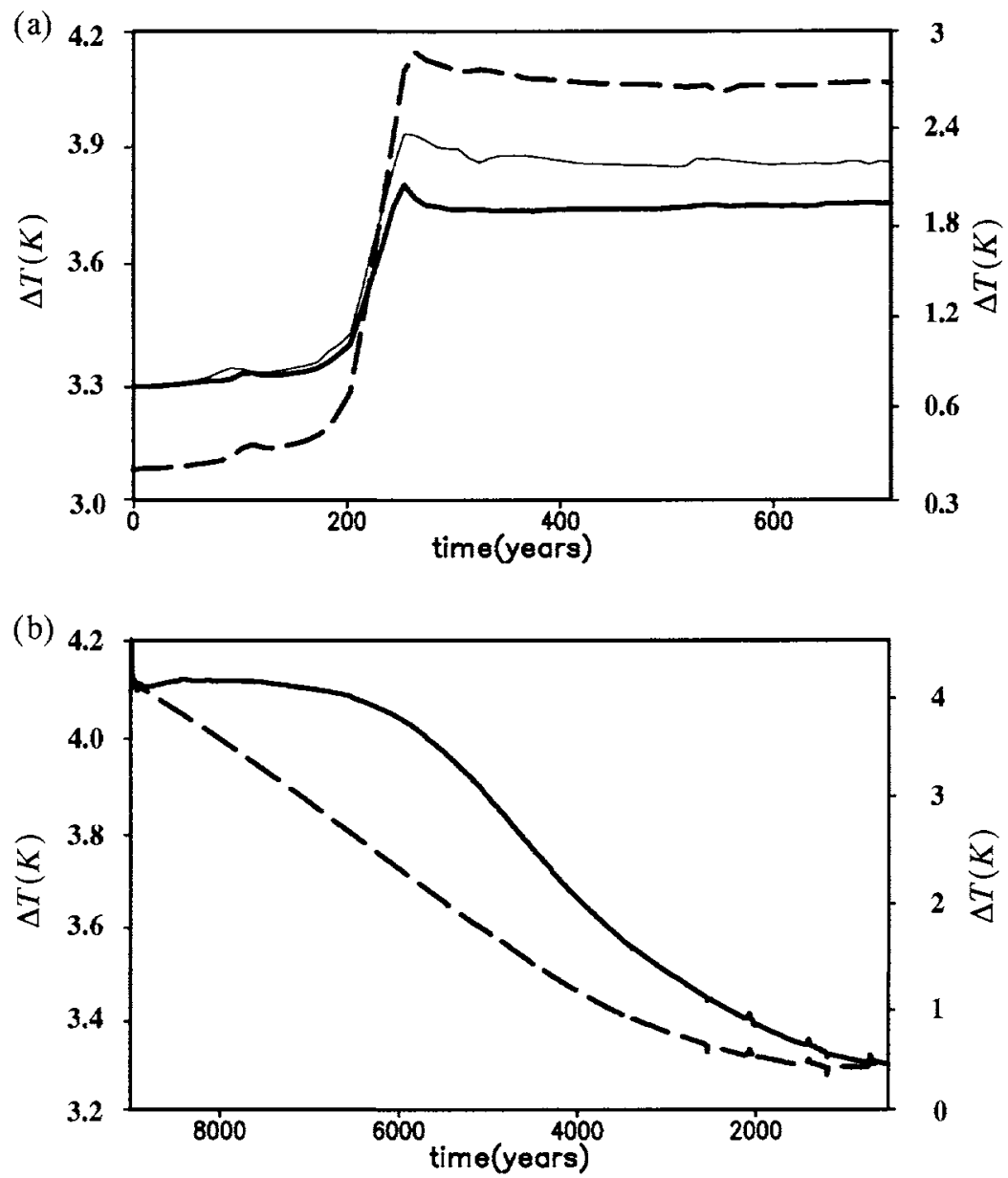

Figure 6. Simulated temperature differences in the $\mathrm{CO}_{2}$ sensitivity experiment (a) and the Holocene experiments $(b)$ between northern Africa $\left(10^{\circ} \mathrm{N}-30^{\circ} \mathrm{N}\right)$ and tropical North Atlantic $\left(0^{\circ} \mathrm{N}-30^{\circ} \mathrm{N}\right)$ (full line, left scale) and between Central Asia $\left(30^{\circ} \mathrm{N}-50^{\circ} \mathrm{N}\right)$ and tropical North Atlantic (dashed line, right scale). The thick lines in (a) refer to the results from the fully coupled model, and the thin line refers to the results of the atmosphere-ocean-only model.

Eurasian continent and the tropical Atlantic Ocean, but not the regional gradient of surface temperatures between northern Africa and the tropical North Atlantic. In the $\mathrm{CO}_{2}$ sensitivity experiment, transient large-scale and regional-scale temperature gradients look similar (Figure 6a). Hence it is hard to judge whether large-scale or regional-scale land-ocean contrast affects the African monsoon more strongly.

In Figure $5 \mathrm{~b}$ (thin lines) the precipitation changes computed in the atmosphereocean-only model, hence in a model configuration, in which the vegetation pattern is kept at a pre-industrial condition, are also included. It can be seen that without the feedback between atmosphere and vegetation dynamics, amplitude and rate of increase in Saharan precipitation are smaller. The transient behavior of precipitation 
changes, however, remains qualitatively the same. Interestingly, the temperature gradient between land surface and ocean surface is stronger in the simulation without vegetation dynamics than in the fully coupled model (Figure 6a). Hence it has to be questioned whether the strength of the African summer monsoon depends on the land-ocean temperature contrast only.

Eltahir (1996) and Eltahir and Gong (1996) suggested that the dynamics of the monsoon circulation over West Africa are regulated by the meridional distribution of boundary-layer entropy. In their theory the dynamics of the moist atmosphere across the land-ocean boundary are the dominant factor which determines the strength of the African summer monsoon. This theory contrasts with Charney's (1975) theory and simulations by Xue and Shukla (1993) which emphasize the dynamics of a dry atmosphere across the savanna-desert border. One important implication of the land-atmosphere-ocean interaction mechanism proposed by Eltahir and Gong (1996) is that the variability in the sea-surface temperatures off the coast of West Africa and/or changes in land cover in the coastal region of West Africa may play a more important role in the regional monsoon climate than do changes in land cover near the desert border. By using a zonally symmetric model of West Africa, Zheng and Eltahir (1998) found that, consistently, land-cover changes along the border between Sahara and Sahel have a minor impact on the simulated monsoon circulation, while deforestation along the West African coast - which more strongly affects boundary-layer entropy - triggered a collapse of the monsoon circulation.

We have not tested the sensitivity of CLIMBER-2 to Saharan versus Sahelian land-cover change in detail. However, Kubatzki (2000), by using CLIMBER-2.1, found that a reduction of trees and grassland in the region between Sahara and West African coast from mid-Holocene values to pre-industrial values (i.e., a reduction of tree cover by $9 \%$ and grassland by $31 \%$ ) yielded a reduction in Saharan vegetation coverage from 0.71 to 0.56 . This high sensitivity of Saharan climate to changes in land cover south of the Sahara is consistent with Eltahir's theory.

Claussen (1997) demonstrated that land-cover change and subsequent vegetation - atmosphere interaction in the Sahara can strongly modify the African summer monsoon. He showed that changes in the atmospheric energy budgets and large-scale zonal atmospheric circulation arising from the land-cover change are consistent with Charney's theory. However, this result does not directly conflict with Eltahir's theory, because a change in land cover always yields a change in boundary-layer entropy. In his three-dimensional, global atmosphere-biome model, Claussen (1997) found a strong increase in West African summer monsoon and an increased gradient in moist static energy between land and ocean, but a weaker temperature gradient between land surface and ocean surface, when the western Sahara was covered by savanna. Claussen's (1997) results and the earlier numerical experiments by Xue and Shukla (1993) indicate that besides the regional atmosphere ocean contrast which Eltahir's theory focusses on, large-scale processes can affect the African summer monsoon as suggested by Charney (1975). The African sum- 
Table I

Differences in zonally averaged vertical velocity $w[\mathrm{~mm} / \mathrm{s}]$, in the deviation $w^{*}[\mathrm{~mm} / \mathrm{s}]$ of local vertical velocity from the zonal mean, in specific humidity $\left[10^{-4} \mathrm{~kg} / \mathrm{kg}\right]$, and vertical moisture flux $w q\left[10^{-4} \mathrm{~mm} / \mathrm{s}\right]$ between the pre-industrial simulation and the last 100 years of a simulation with atmospheric $\mathrm{CO}_{2}$ concentration of 1000 ppmv and a paleoclimate simulation of the mid-Holocene at 6000 years before present, respectively. Differences in vertical moisture flux are split into dynamic contribution $q \Delta w$ and a thermodynamic component $w \Delta q$ where $w=\langle w\rangle+w^{*}$. All values are taken over the Sahel/Sahara region $\left(10^{\circ} \mathrm{N}-30^{\circ} \mathrm{N}\right)$ for boreal summer. Values in brackets refer to the same simulations but with land cover kept constant at pre-industrial conditions

\begin{tabular}{lcl}
\hline & 1000 ppmv & Holocene \\
\hline$\Delta\langle w\rangle$ & $0.11(0.10)$ & $0.10(0.07)$ \\
$\Delta w^{*}$ & $0.35(0.30)$ & $1.09(0.75)$ \\
$\Delta q$ & $3.2(2.7)$ & $1.9(0.9)$ \\
$q \Delta w$ & $18.0(15.8)$ & $46.1(32.0)$ \\
$w \Delta q$ & $18.7(15.8)$ & $11.1(5.4)$ \\
\hline
\end{tabular}

mer monsoon appeared to be closely linked to the Asian summer monsoon and the strength of the tropical easterly jet and the African easterly jet. In simulations with reduced Sahara in present-day climate (Claussen, 1997) as well as in paleosimulations of a mid-Holocene greening of the Sahara (Claussen and Gayler, 1997) the tropical easterly jet at $200 \mathrm{hPa}$ was found to be stronger and the African easterly jet at $700 \mathrm{hPa}$ near $15^{\circ} \mathrm{N}$, weaker than in present-day climate and present-day African deserts - in agreement with Xue and Shukla's (1993) desertification experiments. Qualitatively the same changes in tropical zonal air flow were also found in the Holocene experiments using CLIMBER-2 (Kubatzki, 2000). The apparent correlation between time series of precipitation in northern Africa and the largescale temperature contrast between Central Eurasia and tropical North Atlantic for the last 9000 years seen in Figure $6 \mathrm{~b}$ is consistent with this concept.

In CLIMBER-2, precipitation is not directly related to horizontal temperature or entropy gradients, but it is computed from vertical motion and humidity. To further explore the differences in mechanisms between paleo-monsoon changes and the equilibrium response of African summer monsoon to changes in atmospheric $\mathrm{CO}_{2}$ concentrations we have analysed the vertical moisture flux over northern Africa. In Table I we have listed changes in vertical motion, specific humidity and vertical moisture transport. 
The difference in zonally averaged vertical velocity $\Delta\langle w\rangle$ reflects changes in the zonal mean Hadley circulation. Differences in both experiments are positive, i.e., the intensity of the Hadley circulation increases owing to Holocene changes in insolation and owing to an increase in atmospheric $\mathrm{CO}_{2}$. Both changes in $\Delta\langle w\rangle$ are of similar magnitude. In CLIMBER-2 the strength of mean-meridional circulation increases with the meridional temperature difference and the cube of the zonal mean temperature.

The azonal component of the vertical velocity $w^{*}$ (i.e., the deviation between local and zonally averaged vertical velocity) is larger in the Holocene experiment than in the 1000-1 simulation. The strength of $w^{*}$ can be interpreted as the strength of the African monsoon. $w^{*}$ grows with the temperature contrast between land and ocean. During boreal summer, the temperature contrast, and hence $w^{*}$, is larger in both simulations, the Holocene experiment and the $\mathrm{CO}_{2}$ sensitivity experiment, than in the control simulation.

In both experiments, the specific near-surface humidity $q$ over the Sahel/Sahara region increases in comparison with the control simulation. However, $q$ is stronger in the 1000-1 experiment than in the Holocene experiment, because the ocean surface becomes warmer and thus evaporation increases in the 1000-1 experiment.

Changes in humidity and in vertical velocity affect the vertical moisture transport $w q$ in different ways. In the 1000-1 simulation, the air over the Sahel/Sahara region is moister than in the Holocene simulation; however, the vertical velocity is stronger in the Holocene simulation than in the 1000-1 simulation. The latter process seems to be the dominant factor. Therefore, we find a stronger vertical moisture flux, and hence more precipitation in the Holocene simulation.

Contributions of changes in vertical velocity and humidity to changes in vertical moisture flux $\Delta(w q)$ differ between the 1000-1 and the Holocene simulation. In the 1000-1 simulation, the dynamic component of changes in vertical moisture flux $q \Delta w$ and the thermodynamic component $w \Delta q$ are approximately the same. In the Holocene simulation however, $q \Delta w$ is much larger than $w \Delta q$ which is mainly caused by the azonal component $w^{*}$, i.e. the monsoon-type deviation from the zonal mean $\langle w\rangle$. (Please note that $w=\langle w\rangle+w^{*}$ ). Hence we conclude from our experiments that during the mid-Holocene, the Saharan greening is caused mainly by an increase in the monsoon flow, convective flow and thus monsoon precipitation, while a humidity increase and change in monsoon flow equally contribute to the increase in precipitation in a climate change triggered by an increase in atmospheric $\mathrm{CO}_{2}$ concentrations.

\section{Assessment}

To test the robustness of our experiments, we performed a number of simulations in which parameters implicit in our parameterizations were changed. In our vegetation module, the vegetation fraction is assumed to depend on annual mean 


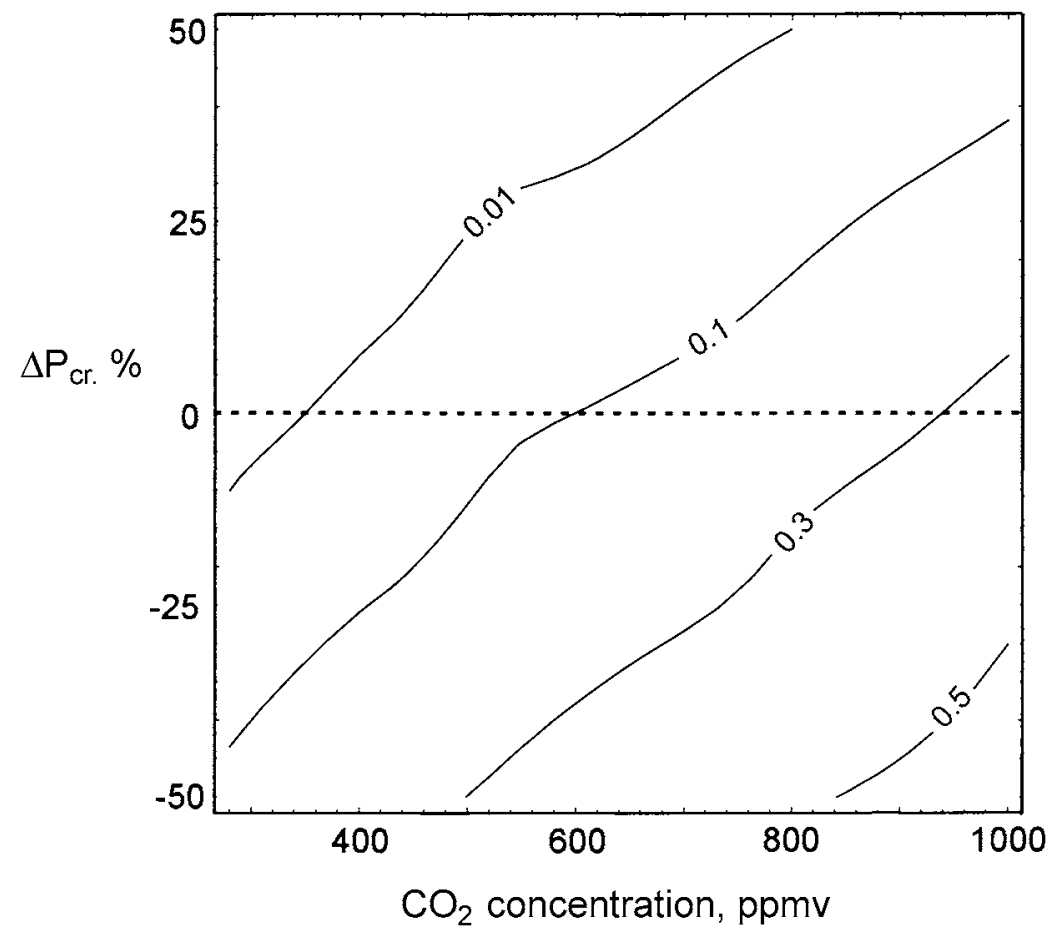

Figure 7. Sensitivity of predicted Saharan vegetation cover to atmospheric $\mathrm{CO}_{2}$ concentration and percentage changes of parameter $P_{c r}$. This parameter which controls the lower limit of precipitation at which vegetation can sustain. The isolines indicate fractional Saharan vegetation cover on average of the last 100 years of each sensitivity experiment during which the model has achieved approximate equilibrium with (constant) $\mathrm{CO}_{2}$ concentration.

temperature and on annual mean precipitation as indicated in Brovkin et al. (1998). We varied the parameter $P_{c r}$ which controls the lower limit of precipitation at which vegetation can be sustained.

It appears that the predicted changes in Saharan vegetation cover depend on $P_{c r}$ as well as on the maximum atmospheric $\mathrm{CO}_{2}$ concentration (see Figure 7). A reduction of $P_{c r}$ yields a stronger expansion of Saharan vegetation and an increase of $P_{c r}$ results in a smaller vegetation expansion. If a large enough value for $P_{c r}$ is chosen, then any vegetation expansion can be suppressed. However, even with an increase of $P_{c r}$ of $50 \%$, some vegetation appears if atmospheric $\mathrm{CO}_{2}$ concentration increases to values of $1000 \mathrm{ppm}$.

Parameters like $P_{c r}$ are obtained as best guesses from data of present-day climate. Therefore, it is useful to test variations of $P_{c r}$ in paleoclimatic simulations. From our Holocene experiments undertaken with different values of $P_{c r}$ we find values of fractional Saharan vegetation cover of $0.65,0.52,0.35$, and 0.19 at $6 \mathrm{ky}$ BP for changes in $P_{c r}$ of $-30 \%, 0 \%,+30 \%$, and $+50 \%$, respectively. Empirical (e.g., Anhuf et al., 1999) and recent theoretical estimates (Doherty et al., 2000) 
yield a mid-Holocene Saharan vegetation cover of approximately 0.5 . Therefore, we conclude that our best guess at $P_{c r}$ for present-day climate leads to model results for mid-Holocene conditions in agreement with other estimates. Moreover, we conclude that results of our sensitivity study which are obtained with a high value of $P_{c r}$ are presumably not realistic, because high values of $P_{c r}$ lead to estimates of mid-Holocene vegetation cover much smaller than paleo-reconstructions suggest.

To assess the significance of our simulations, we have to emphasize that all results were obtained without consideration of any external perturbation of vegetation growth. Sensitivity studies by Kubatzki (2000) indicate that the simulated onset of aridification in northern Africa some 5.500 years ago is only marginally affected by external perturbation. (In the perturbation experiment, vegetation cover was reduced to 0.2 for one year at time intervals of 100 years.) The results differ if vegetation growth is perturbed in our $\mathrm{CO}_{2}$ sensitivity experiments. When we reduced any vegetation cover in the Sahara with a frequency of one to several years, then the vegetation increase was strongly delayed or even suppressed. We attribute his result to the asymetry of time scales of vegetation dynamics diagnosed for densely vegetated and sparsely vegetated desert-like areas. Hence we conclude that vegetation expansion into today's Sahara is possible only, if it is not hampered by perturbations such as grazing.

An increase in atmospheric $\mathrm{CO}_{2}$ concentration may induce a physiological response of vegetation by reducing stomatal conductance and hence transpiration (e.g., Betts et al., 1997). This physiological effect is not accounted for in CLIMBER-2. If this effect were included, then we might expect a slightly stronger near-surface warming over the northern continents as seen in the experiments of Betts et al. (1997). While the temperature contrast between land and ocean could become stronger, horizontal gradients in boundary-layer entropy and moist static energy will presumably change very little owing to the reduction in evaporation. Hence we assume that inclusion of the physiological effect in to CLIMBER-2 would presumably not change our results drastically.

Some of our results concern changes in only one or two grid boxes of CLIMBER-2. For example, the Sahara is, by and large, covered by just one grid box. Nonetheless we consider these 'small-scale' - in comparison with the coarse spatial resolution of CLIMBER-2 - results significant, if they do not depend qualitatively on changes in initial conditions. For example, the Saharan greening during the mid-Holocene or even the pattern of temperature and precipitation changes, including the drying over southern Europe in the $\mathrm{CO}_{2}$ sensitivity experiments, depicted in Figure 3, are considered significant, because these results remain qualitatively the same under different initial conditions or under different boundary conditions (e.g., different $\mathrm{CO}_{2}$ scenarios) or even in different model versions (i.e., they can be found in CLIMBER-2.1 as well as in CLIMBER-2.3).

A more serious limitation of our study concerns the lack of interannual climate variability in CLIMBER-2. Work by Zeng et al. (1999), Wang and Eltahir $(2000 \mathrm{a}-\mathrm{c})$, and Zeng and Neelin (2000) suggests that decadal rainfall variability in 
West Africa can arise from vegetation-atmosphere interaction or from amplification of external forcing, such as changes in subtropical sea-surface temperatures, by vegetation-atmosphere interaction. The atmospheric model in CLIMBER-2 is a dynamic-statistical model which is not designed to simulate interannual variability. Therefore, CLIMBER-2 is not the appropriate tool to explore interannual variability or to examine whether the observed variability in Sahelian rainfall relates to internal, natural variability or to external, for example anthropogenic, perturbation.

\section{Conclusion}

Our results indicate that the greening of the Sahara several thousand years ago is not a paleo-analogue for potential future climate and vegetation changes in northern Africa. Paleoclimatic changes in the African monsoon were presumably triggered by changes in insolation and amplified by a positive, nonlinear feedback mainly between vegetation in northern Africa, atmospheric motion and precipitation. When atmospheric $\mathrm{CO}_{2}$ concentration is enhanced, our model reveals an increase in precipitation in tropical Africa and the Sudan, if the atmospheric $\mathrm{CO}_{2}$ concentration increases are well above levels for pre-industrial climate - in agreement with results from some comprehensive climate models. This change is also amplified by the biogeophysical feedback. Both the rate and the amplitude of Saharan vegetation changes depend on the rate and the upper limit of the increase in atmospheric $\mathrm{CO}_{2}$ concentrations. Intrusion of vegetation into the Sahara can, in principle, occur within a few decades.

Despite the apparent similarity, the increase in vegetation coverage in northern Africa as a result of an increase in atmospheric $\mathrm{CO}_{2}$ concentrations is quantitatively and mechanistically different from the vegetation change owing to insolation changes during the Holocene. As a result of differences in forcing - in the one case, a seasonal and regional change of insolation pattern and in the other case, a globally homogeneous increase in the greenhouse gas $\mathrm{CO}_{2}-$ global patterns of changes in near-surface temperature and precipitation differ. Also the contribution of dynamic effects (stronger convergence and hence, stronger convective flow) and thermodynamic effects (increase in precipitable water owing to stronger evaporation) to changes in the monsoon are different in the Holocene experiment and the $\mathrm{CO}_{2}$ sensitivity experiments. Moreover, comparison of transient monsoon changes suggests that changes in the paleo-monsoon system are governed by the large-scale temperature contrast between the Eurasian continent and the oceans, and hence by changes in tropical air flow, and only to a lesser extent by the regional temperature gradient between northern Africa and tropical North Atlantic. In the $\mathrm{CO}_{2}$ sensitivity experiments, the effect of transient changes in regional temperature gradients is more apparent.

Finally, we would like to emphasize that owing to several limitations of our model (coarse resolution, lack of realistic interannual climate variability), our study 
is not a forecast of future climate change. Likewise, we cannot attribute the past decadal variability of Sahelian drought to natural variability or anthropogenic forcing. Instead, we have presented a sensitivity study on the resilience of the natural Earth system where we have identified the theoretical possibility of potentially rapid climate changes in northern Africa in a greenhouse-gas induced climate warming.

\section{Acknowledgments}

We would like to thank Anja Hünerbein for technical assistance and Alison Schlums for editing. We acknowledge the constructive comments and critique of three anonymous reviewers.

\section{References}

Anhuf, D., Frankenberg, P., and Lauer, W.: 1999, 'Die postglaziale Warmphase vor 8000 Jahren', Geologische Rundschau 51, 454-461.

Berger, A.: 1978, 'Long-Term Variations of Daily Insolation and Quaternary Climatic Change', J. Atmos. Sci. 35, 2362-2367.

Berger, A. and Loutre, M. F.: 1997, 'Long-Term Variations in Insolation and their Effects on Climate, the LLN Experiments', Surveys in Geophysics 18, 147-161.

Betts, R. A., Cox, P. M., Lee, S. E., and Woodward, F. I.: 1997, 'Contrasting Physiological and Structural Vegetation Feedbacks in Climate Change Simulations', Nature 387, 796-799.

Braconnot, P., Joussaume, S., Marti, O., and deNoblet-Ducoudre, N.: 1999, 'Synergistic Feedbacks from Ocean and Vegetation on the African Monsoon Response to Mid-Holocene Insolation', Geophys. Res. Lett. 26 (16), 2481-2484.

Broström, A., Coe, M., Harrison, S. P., Gallimore, R., Kutzbach, J. E., Foley, J. A., Prentice, I. C., and Behling, P.: 1998, 'Land Surface Feedbacks and Paleomonsoons in Northern Africa', Geophys. Res. Lett. 25 19, 3615-3618.

Brovkin, V., Bendtsen, J., Claussen, M., Ganopolski, A., Kubatzki, C., Petoukhov, V., and Andreev, A.: 2002, 'Carbon Cycle, Vegetation and Climate Dynamics in the Holocene: Experiments with the CLIMBER-2 Model', Global Biogeochem. Cycles, accepted.

Brovkin, V., Claussen, M., Petoukhov, V., and Ganopolski, A.: 1998, 'On the Stability of the Atmosphere-Vegetation System in the Sahara/Sahel Region', J. Geophys. Res. 103(D24), $31613-31624$.

Charney, J. G.: 1975, 'Dynamics of Deserts and Droughts in the Sahel', Quart. J. Roy. Meteorol. Soc. 101, 193-202.

Claussen, M.: 1997, 'Modelling Biogeophysical Feedback in the African and Indian Monsoon Region', Clim. Dyn. 13, 247-257.

Claussen, M.: 2001, 'Biogeophysical Feedbacks and the Dynamics of Climate', in Schulze, E. D., Harrison, S. P., Heimann, M., Holland, E. A., Lloyd, J., Prentice, I. C., and Schimel, D. (eds.), Global Biogeochemical Cycles in the Climate System, Academic Press, San Diego, pp. 61-71.

Claussen, M., Brovkin, V., Ganopolski, A., Kubatzki, C., and Petoukhov, V.: 1998, 'Modelling Global Terrestrial Vegetation - Climate Interaction', Phil. Trans. Roy. Soc. London B 353, 53-63.

Claussen, M. and Gayler, V.: 1997, 'The Greening of Sahara during the Mid-Holocene: Results of an Interactive Atmosphere - Biome Model', Global Ecol. Biogeog. Lett. 6, 369-377. 
Claussen, M., Kubatzki, C., Brovkin, V., Ganopolski, A., Hoelzmann, P., and Pachur, H. J.: 1999, 'Simulation of an Abrupt Change in Saharan Vegetation at the End of the Mid-Holocene', Geophys. Res. Lett. 24 (14), 2037-2040.

Colman, R. A., Power, S. B., MacAvaney, B. J., and Dahni, R. R.: 1995, 'A Non-Flux-Corrected Transient $\mathrm{CO}_{2}$ Experiment using the BMRC Coupled Atmosphere/Ocean GCM.', Geophys. Res. Lett. 22, 3047-3050.

Cramer, W., Bondeau, A., Woodward, F. I., Prentice, I. C., Betts, R. A., Brovkin, V., Cox, P. M., Fisher, V., Foley, J. A., Friend, A. D., Kucharik, C., Lomas, M. R., Ramankutty, N., Sitch, S., Smith, B., White, A., and Young-Molling, C.: 2001, 'Global Response of Terrestrial Ecosystem Structure and Function to $\mathrm{CO}_{2}$ and Climate Change: Results from Six Dynamic Global Vegetation Models', Global Change Biology 7, 357-373.

Cubasch, U., Meehl, G. A., Boer, G. J., Stouffer, R. J., Dix, M., Noda, A., Senior, C. A., Raper, S., and Yap, K. S.: 2001, 'Projections of Future Climate Change', in Houghton, J. T., Ding, Y., Griggs, D. J., Noguer, M., van der Linden, P., Dai, X., Maskell, K., and Johnson, C. I. (eds.), Climate Change 2001: The Scientific Basis. Contribution of Working Group I to the Third Assessment Report of the Intergovernmental Panel on Climate Change, Cambridge University Press, Cambridge, U.K. and New York, U.S.A., 881 pp.

Doherty, R., Kutzbach, J., Foley, J., and Pollard, D.: 2000, 'Fully Coupled Climate/Dynamical Vegetation Model Simulations over Northern Africa during the Mid-Holocene', Clim. Dyn. 16, 561-573.

Eltahir, E. A. B.: 1996, 'Role of Vegetation in Sustaining Large-Scale Atmospheric Circulation in the Tropics', J. Geophys. Res. 101 (D2), 4255-4268.

Eltahir, E. A. B. and Gong, C.: 1995, 'Dynamics of Wet and Dry Years in West Africa', J. Climate 9(5), 1030-1042.

Frenzel, B., Pesci, M., and Velichko, A. A. (eds.): 1992, Atlas of Paleoclimates and Paleoenvironments of the Northern Hemisphere: Late Pleistocene - Holocene, Geographical Research Institute, Budapest, $153 \mathrm{pp}$.

Ganopolski, A., Kubatzki, C., Claussen, M., Brovkin, V., and Petoukhov, V.: 1998a, 'The Influence of Vegetation-Atmosphere-Ocean Interaction on Climate during the Mid-Holocene', Science 280, 1916-1919.

Ganopolski, A., Petoukhov, V., Rahmstorf, S., Brovkin, V., Claussen, M., Eliseev, A., and Kubatzki, C.: 2001, 'CLIMBER-2: A Climate System Model of Intermediate Complexity. Part II: Validation and Sensitivity Tests', Clim. Dyn. 17, 735-751.

Ganopolski, A., Rahmstorf, S., Petoukhov, V., and Claussen, M.: 1998b, 'Simulation of Modern and Glacial Climates with a Coupled Global Model of Intermediate Complexity', Nature 391, 351-356.

Harrison, S. P., Jolly, D., Laarif, F., Abe-Ouchi, A., Dong, B., Herterich, K., Hewitt, C., Joussaume, S., Kutzbach, J. E., Mitchell, J., de Noblet, N., and Valdes, P.: 1998, 'Intercomparison of Simulated Global Vegetation Distributions in Response to 6kyr BP Orbital Forcing', J. Climate 11, 2721-2742.

Hoelzmann, P., Jolly, D., Harrison, S. P., Laarif, F., Bonnefille, R., and Pachur, H.-J.: 1998, 'MidHolocene Land-Surface Conditions in Northern Africa and the Arabian Peninsula: A Data Set for the Analysis of Biogeophysical Feedbacks in the Climate System', Global Biogeochem. Cycles 12, 35-51.

Jolly, D., Harrison, S. P., Damnati, B., and Bonnefille, R.: 1998, 'Simulated Climate and Biomes of Africa during the Late Quarternary: Comparison with Pollen and Lake Status Data', Quat. Sci. Rev. 17 (6-7), 629-657.

Joussaume, S., Taylor, K. E., Braconnot, P., Mitchell, J. F. B., Kutzbach, J.E., Harrison, S. P., Prentice, I. C., Broccoli, A. J., Abe-Ouchi, A., Bartlein, P. J., Bonfiels, C., Dong., B., Guiot, J., Herterich, K., Hewit, C.D., Jolly, D., Kim, J. W., Kislov, A., Kitoh, A., Loutre, M. F., Masson, V., McAvaney, B., McFarlane, N., de Noblet, N., Peltier, W. R., Peterschmitt, J.Y., Pollard, D., Rind, D., Royer, 
J. F., Schlesinger, M. E., Syktus, J., Thompson, S., Valdes, P., Vettoretti, G., Webb, R. S., and Wyputta, U.: 1999, 'Monsoon Changes for 6000 Years Ago: Results of 18 Simulatins from the Paleoclimate Modeling Intercomparison Project (PMIP)', Geophys. Res. Lett. 26 (7), 859-862.

Keeling, C. D.: 2000, 'Atmospheric $\mathrm{CO}_{2}$ Concentrations - Mauna Loa Observatory, Hawaii, 19581999', Report NDP-001, CDIAC, ORNL, Oak Ridge, U.S.A.

Kubatzki, C.: 2000, Wechselwirkung zwischen Klima und Landoberfläche im Holozän. Dissertation, Fachbereich Geowissenschaften, Freie Universität Berlin, 182 S.

Kubatzki, C., Montoya, M., Rahmstorf, S., Ganopolski, A., and Claussen, M.: 2000, 'Comparison of a Coupled Global Model of Intermediate Complexity and an AOGCM for the Last Interglacial', Clim. Dyn. 16, 799-814.

Kutzbach, J. E., Bonan, G., Foley, J., and Harrison, S. P.: 1996, 'Vegetation and Soil Feedbacks on the Response of the African Monsoon to Orbital Forcing in the Early to Middle Holocene', Nature 384, 623-626.

Kutzbach, J. E. and Guetter, P. J.: 1986, 'The Influence of Changing Orbital Parameters and Surface Boundary Conditions on Climate Simulations for the Past 18,000 Years', J. Atmos. Sci. 43, 17261759.

Kutzbach, H. E., Harrison, S. P., and Coe, M. T.: 2001, 'Land-Ocean-Atmosphere Interactions and Monsoon Climate Change: A Paleoperspective', in Schulze, E. D., Harrison, S. P., Heimann, M., Holland, E. A., Lloyd, J., Prentice, I. C., and Schimel, D. (eds.), Global Biogeochemical Cycles in the Climate System, Academic Press, San Diego, pp. 73-86.

Maslin, M., Sarnthein, M., and Knaak, J.-J.: 1996, 'Subtropical Eastern Atlantic Climate during the Eemian', Naturwissenschaften 83, 122-126.

deMenocal, P. B, Ortiz, J., Guilderson, T., Adkins, J., Sarnthein, M., Baker, L., and Yarusinski, M.: 2000, 'Abrupt Onset and Termination of the African Humid Period: Rapid Climate Response to Gradual Insolation Forcing', Quat. Sci. Rev 19, 347-361.

Neftel, A., Moor, E., Oeschger, H., Stauffer, B., Friedli, H., Lütscher, H., and Siegenthaler, U.: 1990, 'Atmospheric Carbon Dioxide Concentration - Historical Record, Siple Station, in: Trends 90: A Compendium of Data on Global Change', Rep. 36, CDIAC, ORNL, Oak Ridge, U.S.A.

Petit-Maire, N.: 1990, 'Will Greenhouse Green the Sahara?', Episodes 13 (2), 103-107.

Petoukhov, V., Ganopolski, A., Brovkin, V., Claussen, M., Eliseev, A., Kubatzki, C., and Rahmstorf, S.: 2000, 'CLIMBER-2: A Climate System Model of Intermediate Complexity. Part I: Model Description and Performance for Present Climate', Clim. Dyn. 16 1, 1-17.

Prentice, I. C., Jolly, D., and BIOME 6000 members: 2000, 'Mid-Holocene and Glacial-Maximum Vegetation Geography of the Northern Continents and Africa', J. Biogeography 27, 507-519.

Sarnthein, M.: 1978, 'Sand Deserts during Glacial Maximum and Climatic Optimum', Nature 272, 43-46.

Sarnthein, M., Tetzlaff, G., Koopmann, B., Wolter, K., and Pflaumann, U.: 1981, 'Glacial and Interglacial Wind Regimes over the Eastern Subtropical Atlantic and North-West Africa', Nature 293, 193-196.

Spitaler, R.: 1921, Das Klima des Eiszeitalters, Selbstverlag, Prag, 138 pp.

Stocker, T. F., Wright, D. G., and Mysak, L. A.: 1992, 'A Zonally Averaged, Coupled OceanAtmosphere Model for Paleoclimate Studies', J. Climate 5, 773-797.

Texier, D., deNoblet, N., Harrison, S. P., Haxeltine, A., Jolly, D., Joussaume, S., Laarif, F., Prentice, I. C., and Tarasov, P.: 1997, 'Quantifying the Role of Biosphere-Atmosphere Feed-Backs in Climate Change: Coupled Model Simulations for 6000 Years BP and Comparison with Paleodata for Northern Eurasia and Northern Africa', Clim. Dyn. 13, 865-882.

Xue, Y. and Shukla, J.: 1993, 'The Influence of Land Surface Properties on Sahel Climate. Part I: Desertification', J. Climate 6, 2232-2245.

Wang, G. and Eltahir, E. A. B.: 2000a, 'Biosphere-Atmosphere Interactions over West Africa. Part I. Development and Validation of a Coupled Dynamic Model', Quart. J. Roy. Meteorol. Soc. 126, 1239-1260. 
Wang, G. and Eltahir, E. A. B.: 2000b, 'Biosphere-Atmosphere Interactions over West Africa. 2. Multiple Equilibira', Quart. J. Roy. Meteorol. Soc. 126, 1261-1280.

Wang, G. and Eltahir, E. A. B.: 2000c, 'Role of Vegetation Dynamics in Enhancing the LowFrequency Variability of Sahel Rainfall', Water Resour. Res. 36 (4), 1013-1021.

Yu, G. and Harrison, S. P.: 1996, 'An Evaluation of the Simulated Water Balance of Eurasia and Northern Africa at 6000 y BP using Lake Status Data', Clim. Dyn. 12, 723-735.

Zeng, N. and Neelin, J. D.: 2000, 'The Role of Vegetation-Climate Interaction and Interannual Variability in Shaping the African Savanna', J. Climate 13, 2665-2670

Zeng, N., Neelin, J. D., Lau, K.-M., and Tucker, C. J.: 1999, 'Enhancement of Interdecadal Climate Variability in the Sahel by Vegetation Interaction', Science 286, 1537-1540.

Zheng, X. and Eltahir, E. A. B.: 1998, 'The Role of Vegetation in the Dynamics of West African Monsoons', J. Climate 11, 2078-2096.

(Received 25 April 2001; accepted 16 April 2002) 